\title{
Spatial changes in the sensitivity of Atlantic cod to climate-driven effects in the plankton
}

\author{
Grégory Beaugrand ${ }^{1,2, *}$, Richard R. Kirby ${ }^{2,3}$ \\ ${ }^{1}$ Centre National de la Recherche Scientifique (CNRS), Laboratoire d'Océanologie et de Géosciences, UMR LOG CNRS 8187, \\ Université des Sciences et Technologies Lille, 1 BP 80, 62930 Wimereux, France \\ ${ }^{2}$ Sir Alister Hardy Foundation for Ocean Science, The Laboratory, Citadel Hill, Plymouth PL12PB, UK \\ ${ }^{3}$ School of Marine Science and Engineering, University of Plymouth, Drake Circus, Plymouth PL4 8AA, UK
}

\begin{abstract}
Recent strategies to sustain fish stocks have suggested a move towards an ecosystem based fisheries management (EBFM) approach. While EBFM considers the effect of fishing at the ecosystem level, it generally struggles with climate-driven environmental variability. In this study we show that the position of a fish stock within its distributional range or thermal niche (we use Icelandic and North Sea cod as examples of stocks at the centre and edge of their niche, respectively) will influence the relative importance of fishing and climate on abundance. At the warmer edge of the thermal niche of cod in the North Sea, we show a prominent influence of climate on the cod stock that is mediated through temperature effects on the plankton. In contrast, the influence of climate through its effects on plankton appears much less important at the present centre of the niche around Iceland. Recognising the potentially strong effect of climate on fish stocks, at a time of rapid global climate change, is probably an important prerequisite towards the synthesis of a cod management strategy.
\end{abstract}

KEY WORDS: Climate change $\cdot$ Cod $\cdot$ Plankton $\cdot$ Temperature $\cdot$ Fishing

\section{INTRODUCTION}

Reversing the global decline in marine fish stocks that is affecting commercial fisheries and the ecological condition of the oceans (Jackson 2008) is the goal of fisheries management. The Atlantic cod Gadus morhua L. is an important commercial, continental-shelf groundfish found in regions that have a mean $100 \mathrm{~m}$ depth temperature ranging from 0 to $16^{\circ} \mathrm{C}$ (Sundby 2000) and an annual sea surface temperature (SST) between 0 and $14^{\circ} \mathrm{C}$ (Fig. 1). Between 1980 and 2000, North Atlantic cod stocks halved from 1.6 to $0.8 \mathrm{Mt}$ (Brander 2003). In some regions where cod has declined in abundance, trophic cascades have been observed altering ecosystem trophodynamics (e.g. Frank et al. 2005). As with most other commercially exploited marine species, overfishing is considered responsible for the decline of cod. As a result, the man-

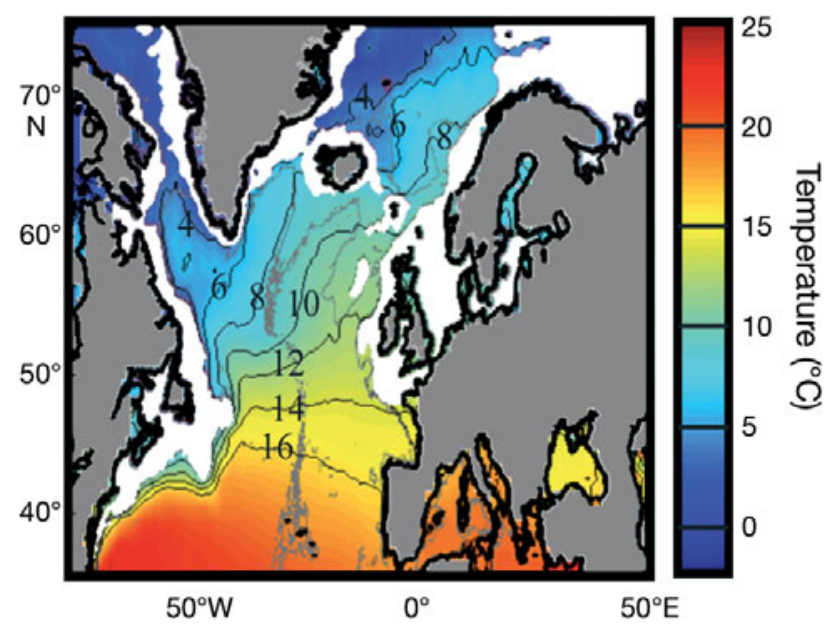

Fig. 1. Gadus morhua. Mean annual sea surface temperature (SST) and the spatial distribution of the Atlantic cod (white area) 
agement of marine resources such as cod is focused on controlling fishing mortality (e.g. the establishment of quota controls to moderate top-down effects). However, despite a moratorium of more than $17 \mathrm{yr}$ on cod fishing in Newfoundland, and reduced fishing effort in the North Sea, neither stock is recovering.

Recent strategies to sustain fish stocks have suggested a move towards an ecosystem based fisheries management (EBFM) approach (Pikitch et al. 2004). While EBFM considers the effect of fishing at the ecosystem level, beyond the effect on the target species, it generally struggles with climate-driven environmental variability that can exert bottom-up control of fish stocks (Beaugrand et al. 2003, Platt et al. 2003). Lack of consideration of environmental effects is especially surprising when contemporary biogeography indicates that many spatial patterns in species' distributions reflect climate (Lomolino et al. 2006), and it is at a time when the biosphere is experiencing rapid climate change (IPCC 2007).

The potential spatial distribution of a species can be estimated by identifying its ecological niche (Lomolino et al. 2006). In the present study we assessed the niche of adult cod using sea surface temperature (SST). We assume that climate exerts its major influence on cod through the effects of temperature on larval development and plankton food availability, since the pelagic larval stage is a critical life cycle phase affecting recruitment (Beaugrand et al. 2003). Our studies of the Atlantic cod indicate that the position of a fish stock within its thermal niche will influence its vulnerability to climate, and hence the relative importance of environmental variation (bottom-up controls) and commercial fishing (top-down controls) on abundance.

\section{MATERIALS AND METHODS}

\subsection{Plankton data}

Plankton data were collected by the continuous plankton recorder (CPR) survey, an upper-layer plankton monitoring programme operated on a routine monthly basis in the North Atlantic and North Sea since 1946 (Reid et al. 2003). Sampling is by a highspeed upper-layer plankton recorder towed at a standard depth of $\sim 6.5 \mathrm{~m}$ behind merchant ships. Seawater enters the CPR through a front aperture, and the plankton is retained on a moving band of silk gauze with a $270 \mu \mathrm{m}$ mesh size that is slowly wound into a tank of formalin. In the laboratory, the silk gauze is cut into sections (a CPR sample), each representing the plankton from $3 \mathrm{~m}^{3}$ of water taken during 10 nautical miles $(18 \mathrm{~km})$. The methods of CPR sampling and analysis remain consistent throughout the time series. Up to 450 taxa are identified and enumerated.

\subsection{Calculation of plankton indicators}

The calculation of the plankton index of larval cod survival is presented in Beaugrand et al. (2003) and reflects the quality and quantity of potential zooplankton prey. The index is based on the fact that larval cod occur between March and September. Feeding of cod larvae/juveniles gradually progresses from mainly copepod eggs to copepod and euphausiid nauplii and then to a copepod dominated diet until July and finally to a progressive replacement of the copepod-based diet by euphausiids and other fish larvae from August. Among copepods, Calanus finmarchicus and Pseudocalanus spp. are the main prey. The index is based on the abundance (no. of individuals per CPR sample) of Calanus finmarchicus, Pseudocalanus spp., and euphausiids. The size composition of prey (calanoid copepod) is also included and calculated by assuming all copepods are females (minimum size), which holds true in CPR samples. Total calanoid copepod biomass per CPR sample was used as a quantitative indicator of food for larval/juvenile cod and was estimated from the size of each calanoid copepod (a total of 108 calanoid species), their abundance, and allometric relationships (Beaugrand et al. 2003). All parameters were then combined and a standardised principal component analysis (PCA) was applied with observations as years (period 1958 to 2007) and months between March and September, and biological indicators (a total of 5 indicators) as variables. Since the occurrence of Calanus helgolandicus is unusual around Iceland it was not included this time. The spatial domain around Iceland was between $62^{\circ}$ and $66^{\circ} \mathrm{N}$ and $27^{\circ}$ and $11^{\circ} \mathrm{W}$ (a total of $7078 \mathrm{CPR}$ samples was considered, an average of 141 per annum) and for the North Sea it was between $50.5^{\circ}$ and $60.5^{\circ} \mathrm{N}$ and $3.5^{\circ}$ and $9.5^{\circ} \mathrm{E}$ (a total of 54507 CPR samples was considered, an average of 1091 per annum). More information on the plankton index can be found in Beaugrand \& Kirby (2009).

\subsection{Cod data}

Cod recruitment data (1 yr old for the North Sea and 3 yr old for Iceland) and spawning stock biomass (SSB) were obtained from ICES (www.ices.dk). Data of probability of cod occurrence was obtained from Fishbase (http://www.fishbase.org).

\subsection{Temperature data}

Observed SST data (1960 to 2005) were extracted from the International Comprehensive Ocean-Atmosphere Data Set (http://icoads.noaa.gov). To assess the 
potential impact of changes in SST, data (1990 to 2100) from the European Centre Hamburg (ECHAM) 4 model were used; these data are projections of monthly skin temperature equivalent above the sea to SST (http://ipcc-ddc.cru.uea.ac.uk). Data used here are modeled data based on scenarios A2 (concentration of carbon dioxide of 856 ppm by 2100) and B2 (concentration of carbon dioxide of 621 ppm by 2100) (IPCC 2007). Scenario A2 supposes an increase of $\mathrm{CO}_{2}$ similar to that currently observed. Scenarios A2 and B2 reflect world populations of 15.1 and 10.4 billion people in 2100, respectively (IPCC 2007).

\subsection{Calculation of the thermal niche of cod}

The thermal niche of cod was assessed by representing data of cod occurrence from Fishbase as a function of SST. First, only maximum values were retained to draw the contour of the niche. Second, a 1-order sim-

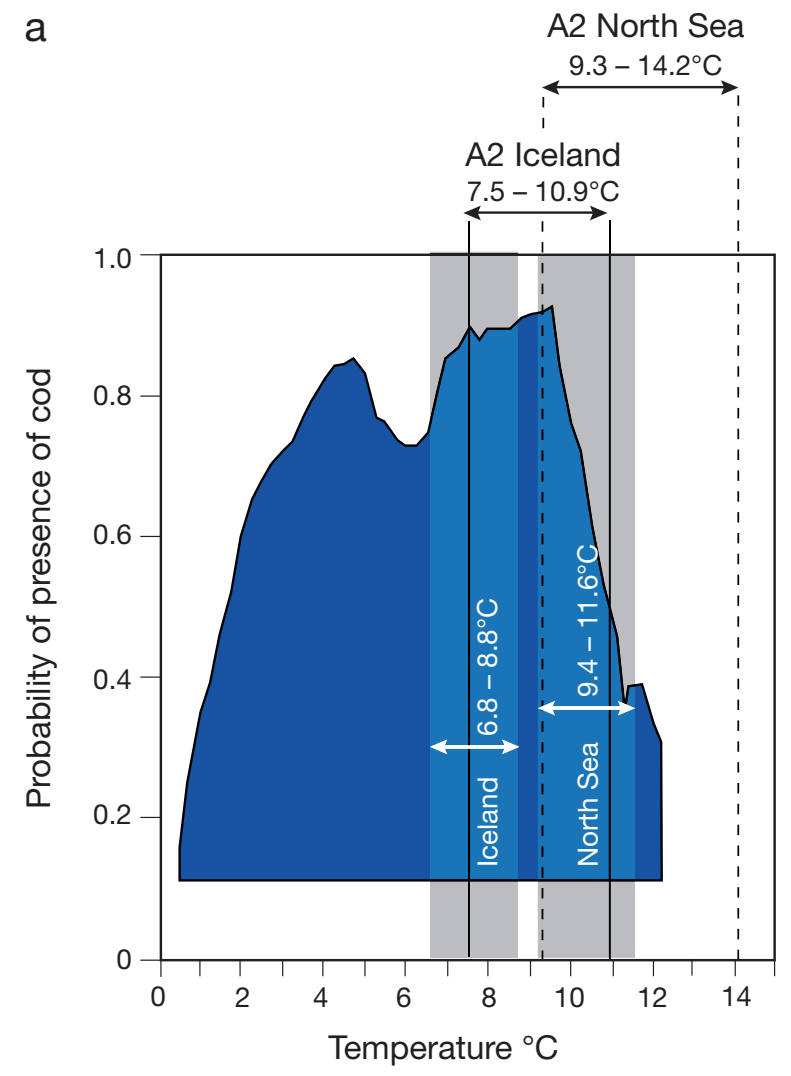

ple moving average was applied on maximum values. This was done to diminish the influence of outliers.

\subsection{Correlation analyses}

Correlations were calculated to assess the strength of the relationships between plankton and cod recruitment in the North Sea (cod recruitment at age 1) and around Iceland (cod recruitment at age 3). The probability of significance of the coefficient of correlation was adjusted to correct for temporal autocorrelation (Pyper \& Peterman 1998).

\section{RESULTS}

The thermal niche shows that the optimal conditions for cod lie between 4 and $9^{\circ} \mathrm{C}$ (Fig. 2a). In the North Sea, the examination of cod recruitment as a function
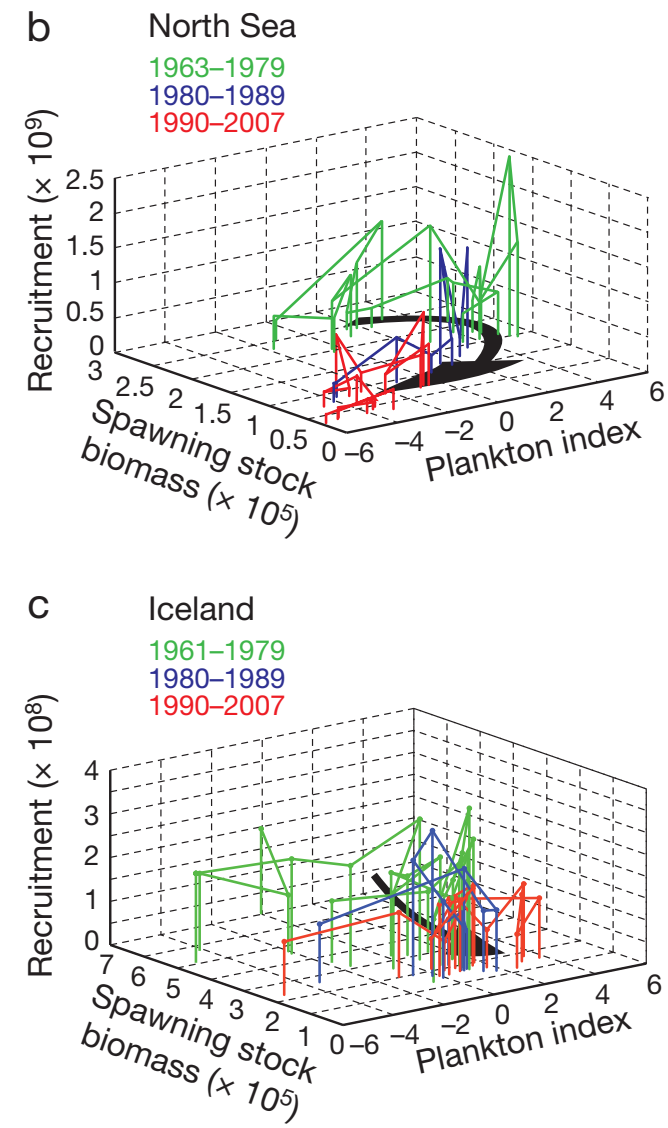

Fig. 2. Gadus morhua. Thermal niche of cod and the effect of spawning stock biomass (SSB) and the plankton index on cod recruitment. (a) Thermal niche of the Atlantic cod based on mean annual SST during the period 1960 to 2005 and probability of cod occurrence. Both observed (1960 to 2005, shaded bars, white text and arrows) and projected (scenario A2, 1990 to 2100, black text and arrows) ranges in annual SST are indicated for Iceland (solid vertical lines) and the North Sea (dashed vertical lines). Scenario B2 (not represented) was also used and gave a similar range of variation in annual SST. (b) Recruitment of cod (as number) at age 1 as a function of SSB (in t) and the plankton index (1 yr lag) in the North Sea. (c) Recruitment of cod (as number) at age 3 as a function of SSB (in $\mathrm{t}$ ) and the plankton index ( $3 \mathrm{yr}$ lag) in Iceland. Black arrows indicate the direction of change 
of SSB and a plankton index (a measure of the quality and quantity of plankton food) reveals that the pathway of change in recruitment parallels that in the plankton index (Fig. 2b). Correlations between the plankton index and cod recruitment at age 1 (with a 1 yr lag) were highly positive ( $r=0.68$, probability corrected for temporal autocorrelation $\left.\mathrm{p}_{\mathrm{ACF}}<0.001\right)$. When no lag was considered, the correlation decreased to 0.51 and was not significant $(\mathrm{r}=0.51, \mathrm{p}=$ 0.09). In contrast, towards the centre of the current distribution and thermal niche of cod around Iceland (Figs. 1 \& 2a), similar fluctuations in temperature and the plankton index have less effect, and so here fishing is the most plausible explanation for the decline in SSB (Fig. 2c); the correlation between the plankton index and cod recruitment at age 3 with a 3 yr lag was small and not significant $\left(r=0.11, \mathrm{p}_{\mathrm{ACF}}>0.01\right)$. We doubt that the low value in the correlation is due either to the reduced sampling effort, which is 1 order of magnitude less than in the North Sea (see 'Materials and Methods'), or the fact that we could only calculate the relationships between the plankton index and cod recruitment at age 3. While the correlation between SST and the plankton index was significantly negative in the North Sea $(r=-0.66, p=0.01)$, this was not so around Iceland $(r=0.35, p=0.15)$, which suggests that the mechanisms at play in the 2 areas are likely to be different.

\section{DISCUSSION}

Our analysis of the influence of the thermal regime on an important commercial fish species shows that the importance of climate can vary depending upon the location of a fish stock within its thermal niche, a result also found by Planque \& Fredou (1999). In the case of cod, climate-mediated changes in the plankton environment are a strong driver of stock abundance towards the southern limit of its spatial distribution, i.e. at the edge of the thermal niche (Fig. 2a). For the North Sea, this indicates that a favourable plankton environment (a positive plankton index) is necessary for cod recovery. Beaugrand et al. (2008) recently provided a macroecological explanation for this spatial pattern in ecosystem sensitivity. Towards the warmer edge of the thermal niche, small changes in temperature will have a large effect on cod through their impact on plankton. Towards the centre of the thermal niche, where the thermal profile represents a broad plateau (Fig. 2a), similar changes in temperature will have less of an effect on the plankton environment, and so other factors, such as fishing, may exert a greater influence of fish abundance.
An understanding of climate variability and how its effects are mediated through the food web appears to be an important prerequisite to better managing exploited species across their spatial range, at least in the case of Atlantic cod and perhaps also other species (Rothschild \& Shannon 2004). At the southern range of cod, resistance (the capacity to tolerate disturbance) to fishing is high due to the positive effect of the thermal regime on growth (Fig. 2a). However, when temperature becomes too high, stock recovery can be affected by the negative effect of temperature on the plankton (Fig. 2a,b). In the North Sea, climate effects through zooplankton are expected to make the stock more sensitive to overfishing. The synergistic influence of fishing and climate (Beaugrand et al. 2003, Brander 2007, Kirby et al. 2009) exacerbates the probability that an opportunistic species may then fill a vacated niche favouring a trophic cascade through the ecosystem; this could explain the collapse of cod in the Eastern Scotian Shelf (Frank et al. 2005). Once such a shift happens, it is unlikely to be reversed by management. In contrast, in Icelandic waters, the negative effect of a colder regime on growth may limit resistance to fishing. Here however, the potential for an alternative ecosystem state is currently low because the plankton environment is more stable at the centre of the niche (Fig. 2a,c).

Our results offer a way to reconcile the alternative views that either fishing or environment control fish stocks (Beaugrand et al. 2003, Myers et al. 1996). Projections of temperature change (IPCC 2007) indicate that Iceland may adopt the thermal characteristics of the North Sea, switching the main driver in Icelandic waters from fishing to the environment (Fig. 2a). In the North Sea, if temperature follows those projections, cod will disappear inevitably as a commercially viable species (Fig. 2a). Fishery biologists should anticipate these scenarios by integrating both climate, plankton, and fishing into EBFM.

Acknowledgements. We thank the owners, masters, and crews of the ships that tow the continuous plankton recorder on a voluntary basis. R.R.K. is a Royal Society Research Fellow.

\section{LITERATURE CITED}

Beaugrand G, Kirby RK (2009) Climate, plankton and cod. Glob Change Biol (in press) doi:10.1111/j.1365-2486.2009. 02063.x

- Beaugrand G, Brander KM, Lindley JA, Souisi S, Reid PC (2003) Plankton effect on cod recruitment in the North Sea. Nature 426:661-664

Beaugrand G, Edwards M, Brander K, Luczak C, Ibañez F (2008) Causes and projections of abrupt climate-driven ecosystem shifts in the North Atlantic. Ecol Lett 11:1157-1168

Brander K (2003) ICES/GLOBEC cod and climate change programme: results and achievements. GLOBEC Int News 9: $20-22$ 
Brander KM (2007) Global fish production and climate change. Proc Natl Acad Sci USA 104:19709-19714

Frank KT, Petrie B, Choi JS, Leggett WC (2005) Trophic cascades in a formerly cod-dominated ecosystem. Science 308: $1621-1623$

IPCC (Intergovernmental Panel on Climate Change) (2007) Climate change 2007: the physical science basis. Cambridge University Press, Cambridge

Jackson JBC (2008) Ecological extinction and evolution in the brave new ocean. Proc Natl Acad Sci USA 105: 11458-11465

Kirby RR, Beaugrand G, Lindley J (2009) Synergistic effects of climate and fishing in a marine ecosystem. Ecosystems 12 : 548-561

Lomolino MV, Riddle BR, Brown JH (2006) Biogeography. Sinauer Associates, New York

Myers RA, Hutchings JA, Barrowman NJ (1996) Hypothesis for the decline of cod in the north Atlantic. Mar Ecol Prog Ser 138:293-308

Editorial responsibility: Geir Ottersen,

Oslo, Norway
Pikitch EK, Santora C, Babcock EA, Bakun A and others (2004) Ecosystem-based fishery management. Science 305:346-347

Planque B, Fredou T (1999) Temperature and the recruitment of Atlantic cod (Gadus morhua). Can J Fish Aquat Sci 56: 2069-2077

Platt T, Fuentes-Yaco C, Frank KT (2003) Spring algal bloom and larval fish survival. Nature 423:398-399

Pyper BJ, Peterman RM (1998) Comparison of methods to account for autocorrelation analyses of fish data. Can J Fish Aquat Sci 55:2127-2140

> Reid PC, Colebrook JM, Matthews JBL, Aiken J (2003) The continuous plankton recorder: concepts and history, from plankton indicators to undulating recorders. Prog Oceanogr 58:117-173

Rothschild BJ, Shannon LJ (2004) Regime shifts and fishery management. Prog Oceanogr 60:397-402

Sundby S (2000) Recruitment of Atlantic cod stocks in relation to temperature and advection of copepod populations. Sarsia 85:277-298

Submitted: August 13, 2009; Accepted: November 24, 2009

Proofs received from author(s): January 14, 2010 